\title{
Effect of Agricultural Extension Program on Smallholders' Farm Productivity: Evidence from Three Peasant Associations in the Highlands of Ethiopia
}

\author{
Asres Elias ${ }^{1}$, Makoto Nohmi ${ }^{2}$, Kumi Yasunobu $^{2} \&$ Akira Ishida $^{3}$ \\ ${ }^{1}$ The United Graduate School of Agricultural Sciences, Tottori University, Japan \\ ${ }^{2}$ Faculty of Agriculture, Tottori University, Japan \\ ${ }^{3}$ Faculty of Life and Environmental Science, Shimane University, Japan \\ Correspondence: Asres Elias, The United Graduate School of Agricultural Sciences, Tottori University, Japan. Tel: \\ 81-80-4550-5224. E-mail: asres97@yahoo.com
}

Received: May 7, 2013 Accepted: June 14, 2013 Online Published: July 15, 2013

doi:10.5539/jas.v5n8p163 URL: http://dx.doi.org/10.5539/jas.v5n8p163

\begin{abstract}
This study evaluates the effect of agricultural extension program participation on farm productivity taking three case study kebeles (peasant associations) in Ethiopia. A total of 1112 plot-level data collected from 300 selected farm households, comprising of extension participants and non-participants, were used in the study. The study begins the estimation with simple Ordinary Least Square (OLS) method. To deal with the potential bias due to the existence of observed and unobserved characteristics, we employed Heckman Treatment Effect Model (HTEM) and Propensity Score Matching (PSM). The OLS result shows that extension participation increases farm productivity by about 6\%. However, both HTEM and PSM clearly reveal the presence of selection bias in extension program participation which leads to underestimation of the OLS estimates. The participation could have increased farm productivity by up to $20 \%$ had it not been to the serious selection bias related to non-farming factors such as involvement in kebele administration, and wealth status of the participants observed during program placement. Our PSM analysis also verifies the positive effect of extension program participation on farm productivity. In conclusion, the extension program has a positive effect on farm productivity in the study area. However, its effect with its current structure and input could have tripled had there been no bias related to extension program participation. This result provides a valuable policy insight in which improving access to diversified and quality agricultural inputs are critically necessary for the participants on top of expanding the program to less resourceful farmers by avoiding any entry barriers in the future.
\end{abstract}

Keywords: extension program participation, farm productivity, selection bias, Ethiopia

\section{Introduction}

Increasing agricultural productivity is a major challenge in Sub-Saharan Africa (SSA), where $62 \%$ of the population (excluding South Africa) depends on agriculture for their livelihoods (Staatz \& Dembele, 2007). Since 1960s, agricultural production in SSA has failed to keep up pace with population growth (Benin, 2006). Improving the productivity, profitability, and sustainability of smallholders farming is therefore the main pathway to get out of poverty (World Development Report [WDR], 2008). It is widely argued that, achieving agricultural productivity growth will not be possible without developing and disseminating improved agricultural technologies that can increase productivity to smallholder agriculture (Asfaw, Shiferaw, Simtowe, \& Lipper, 2012).

Like in many other SSA countries, agriculture is the most important sector for sustaining growth and reducing poverty in Ethiopia. It accounts for $85 \%$ of employment, $50 \%$ of exports, and $43 \%$ of gross domestic product (GDP) (FAO, 2010). However, lack of adequate farm management practices, low level of modern inputs usage, the depletion of soil organic matter and soil erosion, highly rain fed dependent agriculture system are major obstacles to sustain the agricultural production in the country (Grepperud, 1996; Pender \& Gebremedhin, 2007; Kassie, Zikhali, Manjur, \& Edward, 2009). 
In cognizant of these problems, the government of Ethiopia launched a strategy which is known as the Agricultural Development Led Industrialization (ADLI) in 1993 that sets out agriculture as a primary stimulus to generate increased output, employment and income for the people, and as the spring board for the development of the other sectors of the economy (Kassa \& Abebaw, 2004; Gebremedhin, Jalata, \& Hoekstra, 2009). One of the major components of ADLI is the national extension package program known as Participatory Demonstration and Training Extension System (PADETES). The objective of PADETES are to achieve sustainable development in rural areas through increasing farm productivity (yield), reducing poverty, increasing the level of food security, increasing the volume and variety of industrial raw materials (primary products), and producing for the export market (Kassa, 2003; Ethiopian Economics Association [EEA], 2006).

The PADETES program has been focusing on supply-driven intensification which consists of enhanced supply and promotion of improved seeds, fertilizers, on-farm demonstrations of improved farm practices and technologies and close follow up of farmers' plots (Kassa \& Abebaw, 2004; EEA, 2006; Kassa, 2008). Hence, wider dissemination of improved farm technologies, management practices and know-how to the smallholder farmers have been the major activities of the extension program (Kassa, 2003; Gebremedhin et al., 2009; Asfaw et al., 2012).

However, the performance of the agriculture sector has been very dismal in spite of implementing the national extension package program-PADETES. The impacts of the implemented technologies have been mixed, with increased use of fertilizer but poor productivity growth (World Bank, 2006). The country is still vulnerable to recurrent food shortfalls and national food insecurity (Abate et al., 2011). For instance, between 1998 and 2012 the average number of Ethiopians in need of food assistance fluctuated between 3 million and 14 million (IRIN, 2012). The country ranks at $173^{\text {th }}$ out of 187 nations in terms of Human Development Index (UNDP, 2013).

In Ethiopia, there is relatively large literature dealing with issues related to agricultural extension like adoption status of improved agricultural technologies (Feleke \& Zegeye, 2006; Darcon \& Christiaensen, 2007; Gebregziabher \& Holden, 2011; Beshir, Emana, Kassa, \& Haji, 2012 among others). Although these studies provided useful information on the rate of adoption and factors influencing adoption, rigorous impact evaluations of agricultural extension interventions are scanty (Anderson \& Feder, 2007; Gebremedhin et al., 2009; Nega et al., 2010; World Bank, 2010).

Therefore, this study aims at evaluating the impact of agricultural extension program (AE) participation on smallholders' farm productivity using a plot-level data from three rural kebeles of Ethiopia. We started with a baseline model to estimate the impact of AE participation on farm productivity using Ordinary Least Square (OLS).Then we employed Heckman Treatment Effect Model (HTEM) and Propensity Score Matching (PSM) methods to address the problem of selection-bias due to self-selection of farmers into the program and endogenous program placement.

The rest of this paper is organized as follows. The next section describes a conceptual framework that illustrates the main tasks of the program in Ethiopia. The methodology section outlines the econometric procedures employed to estimate the impact of AE participation on farm productivity. Besides, it also outlines the sampling procedures of the study and type of data used for analysis. The results and discussion section provides and discusses the estimated impacts of participation in extension program on farm productivity. The last section summarizes the main findings, and draws some policy implications and outlook for further research.

\section{Conceptual Framework}

The conceptual framework illustrates how agricultural extension program that is used to enhance farmers' knowledge and skills, as well as promote and expand improved technologies affect farm productivity of Ethiopian smallholders. It is a general fact that, agricultural extension and advisory services play an important role in agricultural development and can contribute to improve the welfare of farmers and other people living in rural areas. In spite of this, there are many factors that condition the relationship between extension inputs and outcomes, and these factors act in complex ways.

According to Anderson and Feder (2003) productivity improvements are only possible when there is a gap between actual and potential productivity. They suggest two types of 'gaps' that contribute to the productivity differential, the technology gap and the management gap. Extension can contribute to the reduction of the productivity differential by increasing the speed of technology transfer and by increasing farmers' knowledge and assisting them in improving farm management practices (Feder, Murgai, \& Quizon, 2004). 
To make it understandable and consistent with the objective of this paper and the design of agricultural extension program in Ethiopia, the pathways showing how the extension program impact agricultural productivity are illustrated in Figure 1.

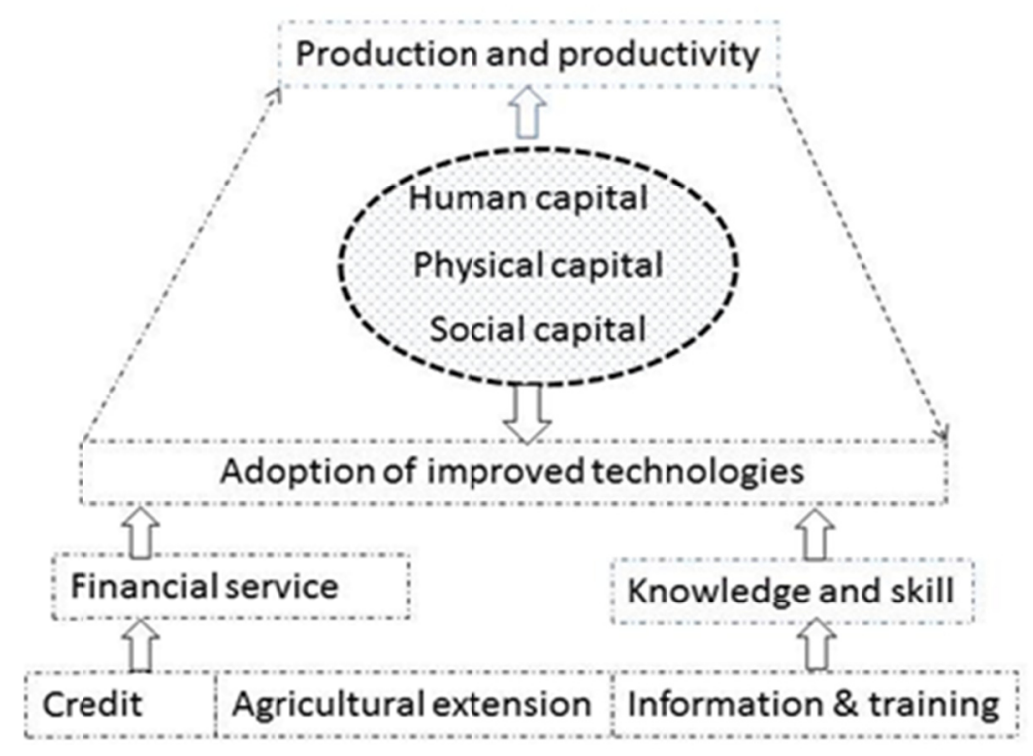

Figure 1. Impact pathway of agricultural extension on farm productivity

The mechanism to increase production and farm productivity through agricultural extension services are mainly tied with adoption of improved seeds, inorganic fertilizers, agro chemicals (herbicide and pesticide) and credit for the Ethiopian smallholder.

By facilitating credit services via cooperatives and microfinance institutions (e.g., credit in cash or in kind), the extension program enhances farmers' financial capacity which leads farmers to adopt improved technologies as well as practices that will ultimately meet their local farm production. Equally important, the extension service facilitates the adoption of improved technologies through awareness creation, acquiring knowledge and skill with dissemination of information and providing training that will ultimately help increase agricultural productivity. However, whether farmers actually adopt improved technologies and practices being promoted by the program is conditioned by several other household and farm level factors as well, such as human capital (sex, age, education level, and labour), physical capital (land size, livestock ownership), social capital (membership in farmers' organizations) and others (soil type, slope of the land, and farm management practices like intensity of ploughing frequency). The possible effect of each variable on land productivity has been hypothesized in Section 3.3.

\section{Data and Methods}

\subsection{Description of the Study Area}

This study was conducted in three selected kebeles ${ }^{\text {Note } 1}$ (i.e., Enerata, Kebi and Wonka) in Gozamin woreda (district) of East Gojjam Zone in the Amhara Regional State, Ethiopia. It is one of the 17 administrative woredas in the Zone (Figure 2). It is found at about a distance of $265 \mathrm{~km}$ far from Bahir Dar city, the Regional capital, and at about $300 \mathrm{~km}$ from Addis Ababa city, the national capital. The woreda has a total area of $1,217.8 \mathrm{~km}^{2}$ and an estimated population of 133,856 , out of which $98 \%$ are living in rural areas (CSA, 2008). There are 14 sector offices and 25 kebeles in the woreda.

Average annual rainfall of the wereda ranges from $1400 \mathrm{~mm}$ to $1800 \mathrm{~mm}$ and have an annual daily average temperature ranging between $11^{\circ} \mathrm{C}$ and $25^{\circ} \mathrm{C}$. It covers three agro-ecological zones with $19 \%$ highland, $65 \%$ midland and 16\% lowland (Gozamin woreda Administration Sector office documents, 2010). About 95\% of total 
crop production is rainfall dependent (Benin, 2006). Generally, the district has a big potential for agricultural activities due to its agro-ecological diversification and dependable rainfall and optimum temperature.

The economy of the woreda is based on plough-based and labour intensive agriculture, which depends mainly on meher rain (main rainy season). Main crops grown in the woreda in order of abundance include teff ${ }^{\text {Note 2 }}$ wheat, maize, barely, check pea, soya bean, oats, niger seed (Neug) and lentil.

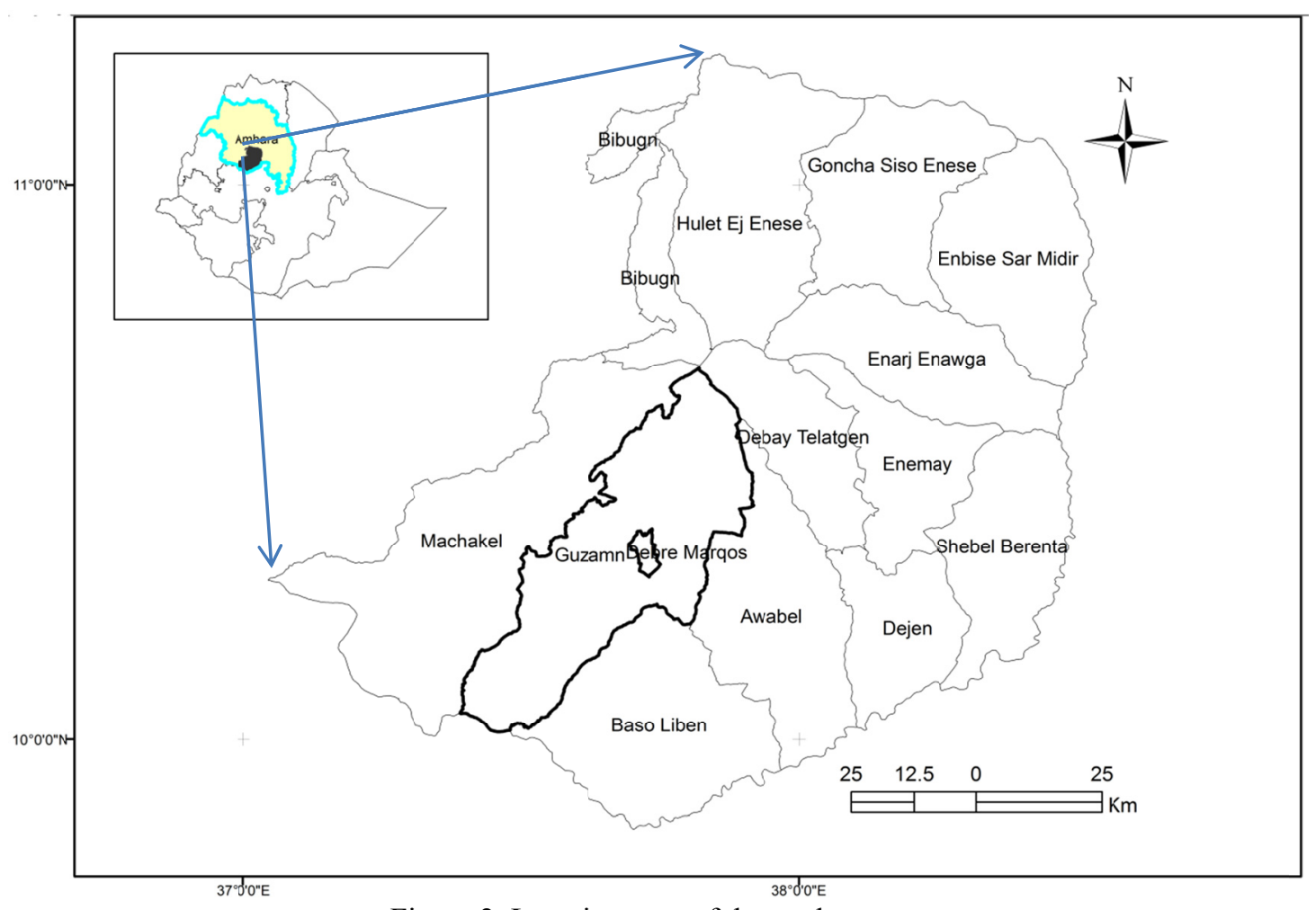

Figure 2. Location map of the study area

\subsection{Data Sources}

The data used in this study were obtained from a household survey conducted in three selected kebeles of Gozamin woreda in May and June 2012. The woreda was selected purposively for satisfying the following criteria; where crop production is widely practiced, where extension program have been implemented for relatively longer period of time, the availability of different agro-ecologies and its representativeness to the Ethiopian highlands. The Ethiopian highlands comprise nearly $45 \%$ of the total land area of 1.12 million square $\mathrm{km}$, and support over $85 \%$ of the country's 82 million population that are overwhelmingly rural.

The three kebeles were randomly selected out of the total 25 kebeles found in the woreda. A multi-stage stratified random sampling technique was employed to select a total of 300 respondent farm households. First, farmers in each selected village were stratified into two groups as participant and non-participant of the extension program. The groups were identified from a list made available by the front-line extension workers, and then the information was confirmed by the farmers. Second, the two groups obtained from the first stage sampling were further stratified in to male and female headed households to ensure, as much as possible, representation of female-headed households in the sample. Data were collected both at household and plot level using structured and pre-tested questionnaire. Interviews and focus group discussions were used to compliment the data obtained through the field survey. The household data consists of demographic characteristics of household head, resource endowment, use of credit, membership in farmers' organization and involvement in kebele administration ${ }^{\text {Note }}$ ${ }^{3}$.The plot level data consists of information on the intensity of input use (improved seed, inorganic fertilizer, compost and agro chemicals for pest and weed control), plot soil quality, plot slope, farm management practice ( such as ploughing frequency) and amount of yield obtained during the 2011/12 main agricultural season for three selected crops (maize, wheat and teff) mainly targeted by the extension program. 


\subsection{Model Specification}

This paper uses a combination of three methods (a benchmark Ordinary Least Square, Heckman's Treatment Effect and Propensity Score Matching) to assess the effect of participation in agricultural extension program on farm productivity.

\subsubsection{The "benchmark" OLS Model}

We start with a baseline model by estimating the impact of agricultural extension program (AE) participation on productivity using OLS.

The model is specified as follows:

$$
Y_{i j}=\beta x_{i}+\psi x_{j}+\delta A E_{i}+\epsilon_{i j}
$$

where, $i$ and $j$ denotes household and plot characteristics, the dependent variable $Y_{i j}$ denotes the natural logarithmic transformation of gross value of crop produced per hectare (expressed in Ethiopian Birr/ ha) ${ }^{\text {Note } 4}, x_{i}$ is a vector of household level explanatory variables (sex, age, education level, labor, livestock ownership, membership in farmers' organization), $x_{j}$ refers plot level explanatory variables (plot size, slope, soil fertility, amount of agrochemicals and inorganic fertilizer, compost, seed type, tenure type, draft power, plot distance from home stead and ploughing frequency), $\beta$ and $\delta$ are vector of parameters to be estimated, $A E_{i}$ is a dummy variable indicating whether or not the $i t h$ household participate in the agricultural extension program and $\epsilon_{i j}$ is the error term. In this "benchmark" specification, the dummy has a constant coefficient, which gives the average treatment for the treated (ATT). The parameter $\delta$ measures the effect of AE program participation on farm productivity.

The effect of explanatory variables on the dependent variable has been hypothesized as follows. The variable age can be considered as an indicator of farming experience, on the other hand, those who are aged households may be reluctant to take up and apply improved technologies as a result the effect of age on crop productivity is ambiguous. Higher level of household education is likely to be associated with higher productivity because education enhances the ability of individuals to utilize technical information and such households would have better use of technologies and farming practice via access to information. On the other hand, there could be cases that educated households have high chance of engaging themselves in other non-farm related activities such as sideline business, involvement in kebele administration that would leave them with little time to spend on their farming activities. Regarding the sex of household head, most studies in developing countries report that female-headed households are the poorest and marginalized people due to their resource and other constraints such as access to credit, market information, assets, technical knowledge, cultural taboos and the likes. Hence we expect male-headed households would have better crop productivity than female headed households.

Physical capital or asset ownership which is usually used as a proxy to explain the wealth status of rural households can be explained by different variables. These are land and livestock which have been shown to overcome credit constraints in rural areas (Thirtle, Beyers, Ismael, \& Piesse, 2003). The estimated coefficient is thus expected to be positive.

Social capital such as membership in farmers' organization might have indirect influence on productivity. This type of organization is mostly targeted by extension workers to disseminate information about improved technologies and farm practices. Therefore those farmers who are members of farmers' organizations might have greater chance to adopt technologies that lead to increase productivity.

OLS estimate of the coefficient for AE participation dummy is unbiased as far as participation is random. However, if the sample of the participants and non-participants is non-random, as it is often the case with non-experimental data like ours, OLS estimates of $\delta$ lead to a biased result. There are several approaches to deal with this problem (e.g. Heckman \& Robb, 1985; Rosenbaum \& Rubin, 1985; Angrist \& Imbens, 1995; Wooldridge, 2010). The sample selection problem may arise from (1) self-selection where the households themselves decide whether or not to participate in extension program, due to differential resource endowments and/or (2) endogenous program placement where those who administer extension program (such as development agents) select households with specific characteristics (relatively poor or reasonably wealthy). As a result, extension participation may not be random that could give us a biased OLS result. To address the possible sample selection bias, we employed Heckman Treatment Effect and Propensity Score Matching techniques as discussed below.

\subsubsection{Heckman Treatment Effect Model}

One of the most widely used approaches to deal with selection bias is the Heckman treatment effect model. The Heckman correction, a two-step statistical approach, offers a means of correcting for non-randomly selected samples. The model can be specified in two steps: 
Outcome equation:

$$
Y_{i j}=\beta x_{i}+\psi x_{j}+\delta A E_{i}+\epsilon_{i j}
$$

This is the same as the OLS equation in Equation (1)

Selection equation:

$$
t_{i}^{*}=Z_{i} \gamma+v_{i}, t_{i}=1 \text { if } t_{i}^{*}>0 \text { and } t_{i}=0 \text { otherwise }
$$

where $t_{i}^{*}$ is the latent endogenous variable i.e., extension participation, $v$ is error term of the selection equation, $Z_{i}$ is a set of exogenous variables predicting the selection of households into the extension program, $\epsilon_{i}$ and $v_{i}$ are bi-variate normal with mean zero and covariance matrix $\left[\begin{array}{cc}\sigma_{\epsilon} & \rho \\ \rho & 1\end{array}\right]$. Where $\rho$ is the correlation between $\epsilon$ and $v$, and $\sigma_{\epsilon}$ is the variance of $\epsilon$. The inverse mills ratio, $\lambda$, is a product of this two i.e., $\hat{\lambda}=\hat{\sigma}_{\epsilon} \hat{\rho}$. Note 5

Selection equation: The probit model is estimated in which extension participation is regressed on a set of household characteristics $Z_{i}$. Variables included in the selection equation are: age of the household head (Age), total land holding of the household (LSize), owned livestock (TLU), family labor in adult equivalent (Adequv), distance from plot to extension center (Pdadist), number of oxen used (Oxenday) and a set of dummies indicating (i) whether the household head is educated (Educ) (ii) whether the household is member of kebele administration (Kebadm) and (iii) whether the household is member of farmers' organization (Frorg). Each of these variables is expected to only affect farm productivity through their impact on participation.

The extension program participation equation:

$$
\begin{gathered}
\text { Pr(AEParticipation } \left.{ }_{\mathrm{i}=1}\right)=\Phi\left[\gamma_{\mathrm{o}}+\gamma_{1} \text { Educ }+\gamma_{2} \text { Kebadm }+\gamma_{3} \text { Frorg }+\gamma_{4} \text { Age }+\right. \\
\left.\gamma_{5} \text { Pdadist }+\gamma_{6} \text { LSize }+\gamma_{7} \text { Adequv }+\gamma_{8} \text { TLU }+\gamma_{9} \text { Oxenday }+v_{i}\right]
\end{gathered}
$$

The choice of the explanatory variables included in $\mathrm{Z}$ is guided by previous empirical literature on the decision of participation in development intervention programs.

Age can influence participation negatively or positively. Older farmers are often viewed as less flexible, and less willing to engage in a new or innovative activity due to fear of risk whereas young farmers may be more risk averse to implement new technologies on their farm. Hence, the influence of age on participation decision is ambiguous. Education might have positive contribution for participation in two ways. Either the farmers select the program due to their ability to understand the cost and benefit of participation in the program as well as easily understand how to implement new technologies (Doss \& Morris, 2001) or extension program might target farmers who are educated due to their capacity of investing in improved technologies through participation in the non-farm sector (Barrett, Reardon, \& Webb, 2001; Cunguara \& Moder, 2011).

Wealth (land, livestock ownership, and family size in adult equivalent scale) might help farmers mitigate incomplete credit and insurance markets (Zerfu \& Larsony, 2011; Ayalew \& Deininger, 2012). Extension program may also target wealthier farmers due to their financial capacity to adopt improved technologies, and thus extension workers might want to deal with them to implement improved technologies promoted by the program.

In the study area, a hard-working and productive farmer is often described by the locals by how well he/she does the different farm activities starting from land preparation to post-harvest. The quality of doing these activities can better be estimated from the number of oxen days a farmer used at plot level, which was collected during our survey. Hence we used number-of-oxen days to characterize each farmer's commitment to farming and such kind of farmers might have high probability of participation in the extension program.

Membership in farmers' organizations can influence participation positively due to either extension workers might find it cheaper to target farmers group which helps them maximize the payoffs from efforts to build farmers capacity to demand advisory service (Benin et al., 2011; Cunguara \& Moder, 2011) or membership in a social group provides opportunities to discuss and observe practices of other members at no cost or time intensity (Gebreegziabher, Mathijs, Maertens, Deckers, \& Bauer, 2011).

Involvement in kebele administration could influence participation positively. One kebele consists of four to seven villages and these villages are often relevant units for government initiatives and program. A village in turn consists of limat budin ${ }^{\text {Note } 6}$, or development team for the implementation of a range of government activities, including mobilizing household labor for community projects. They also have political functions, such as mobilizing support and votes for the ruling party. Extension workers often work closely with limat budin (Cohen 
\& Lemma, 2011; Birhanu, 2012). Hence, being in a position to involve in kebele administration with such kind of network system might increase the probability of participation in government sponsored extension program. We do not expect involvement in kebele administration to be correlated with farm productivity hence it might function as an identifying variable in the sample selection model.

The productivity equation is estimated in which farm productivity is regressed on a set of household and plot level characteristics. This is similar to those variables used in the OLS regression with additional regressor the Inverse Mill's Ratio (IMR) or Lambda (the residuals produced by the first-stage estimate of HTEM) included as a control variable in the productivity equation.

Outcome (farm productivity) equation:

$$
\begin{gathered}
\text { Yield }_{\mathrm{ij}}=\alpha+\delta \text { AEParticipation }_{\mathrm{i}}+\beta_{1} \text { Sex }_{\mathrm{i}}+\beta_{2} \text { Age }_{\mathrm{i}}+\beta_{3} \text { Educ }_{\mathrm{i}}+\beta_{4} \text { TLU }_{\mathrm{i}}+\psi_{1} \text { PlotSize }_{\mathrm{ij}}+\Psi_{2} \text { Slope }_{\mathrm{ij}} \\
+\psi_{3} \text { Soilfertility }_{\mathrm{ij}}+\psi_{4} \text { Agrochemical }_{\mathrm{ij}}+\Psi_{5} \text { Compost }_{\mathrm{ij}}+\psi_{6} \text { Fertlizer }_{\mathrm{ij}}+\psi_{7} \text { Seedtype }_{\mathrm{ij}}+\psi_{8} \text { Dist }_{\mathrm{ij}} \\
+\psi_{9} \text { Tenuretype }_{\mathrm{ij}}+\psi_{10} \text { Oxenday }_{\mathrm{ij}}+\Psi_{11} \text { Labour }+\psi_{12} \text { Ploughingfrequency }_{\mathrm{ij}}+\psi_{13} \text { Cropdummy }_{\mathrm{ij}} \\
+\Psi_{14} \text { Sitedummy }_{\mathrm{ij}}+\text { IMR }_{+} \epsilon_{\mathrm{ij}}
\end{gathered}
$$

where, $i$ is household characteristics and $\mathrm{j}$ denotes plot characteristics.

However, a major limitation of the Heckman treatment model is that it imposes a linear form on the productivity equation and it extrapolates over the regions of no common support, where no similar participant and non-participant exist. But economic theory suggests that imposing such distributional and functional restriction may lead to biased result (Rosenbaum \& Rubin, 1983; Dehejia \& Wahba, 2002; Heckman \& Navarro-Lozano, 2004). Therefore, we complement the analysis with semi-parametric matching approach (Rosenbaum \& Rubin, 1985) to ensure the robustness of our previous model estimations.

\subsubsection{Propensity Score Matching}

Matching is a widely used non-experimental method of evaluation that can be used to estimate the average effect of a particular program (Smith \& Todd, 2005; Caliendo \& Kopeinig, 2008). This method compares the outcomes of program participants with those of matched non-participants, where matches are chosen on the basis of similarity in observed characteristics. Suppose there are two groups of farmers indexed by participation status $\mathrm{P}$ $=0 / 1$, where $1(0)$ indicates farms that did (not) participate in a program. Denote by $y_{i}^{1}$ the outcome (farm productivity) conditional on participation $(\mathrm{P}=1)$ and by $y_{i}^{0}$ the outcome conditional on non-participation $(\mathrm{P}=$ $0)$.

The most common evaluation parameter of interest is the mean impact of treatment on the treated, ATT $=$ $E\left(y_{i}^{1}-y_{i}^{0} \mid p_{i}=1\right)=E\left(y_{i}^{1} \mid p_{i}=1\right)-E\left(y_{i}^{0} \mid p_{i}=1\right)$, which answers the question: 'How much did farms participating in the program benefit compared to what they would have experienced without participating in the program?' Data on $E\left(y_{i}^{1} \mid p_{i}=1\right)$ are available from the program participants. An evaluator's main problem is to find $E\left(y_{i}^{0} \mid p_{i}=1\right)$, since data on non-participants enables one to identify $E\left(y_{i}^{0} \mid P=0\right)$ only. So the difference between $E\left(y_{i}^{1} \mid P=1\right)$ and $E\left(y_{i}^{0} \mid P=1\right)$ cannot be observed for the same farm.

The solution advanced by Rubin (1977) is based on the assumption that given a set of observable covariates X, potential (non-treatment) outcomes are independent of the participation status (conditional independence assumption-CIA): $y_{i}^{0} \perp S_{i} \mid$ X. Hence, after adjusting for observable differences, the mean of the potential outcome is the same for $\mathrm{P}=1$ and $\mathrm{P}=0,\left(E\left(y_{i}^{0} \mid P=1, X\right)=E\left(y_{i}^{0} \mid P=0, X\right)\right)$. This permits the use of matched non-participating farms to measure how the group of participating farms would have performed, if they had not participated.

Like the Heckman treatment effect model, propensity score matching has two-step. First, the propensity score (pscore) for each observation is calculated using logit model for AE participation (estimating a first-step equation similar to equation 3). The second step in the implementation of the PSM method is to choose a matching estimator. A good matching estimator does not eliminate too many of the original observations from the final analysis while it should at the same time yield statistically equal covariate means for treatment and control groups (Caliendo \& Kopeinig, 2008). Hence, a kernel matching algorithm is used to pair each AE participant to similar non-participant using propensity score values in order to estimate the ATT. We also analyzed the data using alternative matching estimators to check the robustness of our results.

As explained above, the main assumption of PSM is selection on observables, also known as conditional independence or unconfoundedness assumption. Therefore, the specification of the propensity score is crucial because the logit model results depend on the unconfoundedness and overlap assumptions among others. 
Unconfoundedness assumption implies that adjusting for differences in observed covariates removes bias in comparisons between the two similar groups that only differ by AE participation. In other words, beyond the observed covariates, there are no unobserved characteristics that are associated both with the potential outcome and the treatment (Imbens \& Wooldridge, 2009). Although unconfoundedness is formally untestable, there are ways to assess its plausibility. To address the unconfoundedness assumption in this study, different measures are taken such as inclusion of many covariates in our propensity score specification to minimize omitted variables bias following the suggestion in Smith \& Todd (2005), then matching is implemented on the region of common support (Heckman et al., 1997). In addition, we employed a placebo regression (Imbens \& Wooldridge, 2009) as a robustness check of the impact estimates to unobserved selection bias. This approach was also used by Abebaw and Haile (2013) and Cunguara and Moder (2011) to test unobserved bias in the impact estimate.

The overlap assumption implies that the conditional distributions of the covariates of AE participants overlap completely with non-participants (Dehejia \& Wahba, 2002; Imbens \& Wooldridge, 2009). There are two formal methods of testing the overlap assumption. The first is to plot the distribution of the propensity scores of AE participants and non-participants and visually assess whether the overlap assumption holds or not. The second method is to compute normalized differences between the two groups (Imbens \& Woolridge, 2009). The normalized difference is given by:

$$
\Delta x=\frac{\bar{x}_{1}-\bar{x}_{0}}{\sqrt{\sigma_{1}^{2}+\sigma_{0}^{2}}}
$$

where $\overline{x_{l}}$ is the mean, and $\sigma_{i}^{2}$ is the sample variance.

\section{Empirical Results}

\subsection{Descriptive Analysis of Bio-Physical and Socioeconomic Conditions}

Tables 1 and 2 indicate a summary of descriptive statistics for household and plot level data respectively. Regarding demographic characteristics, the result revealed that, the average age for participant farmers were slightly less than non-participants. Literacy rate is significantly high for participant household heads (68\%) than those who did not participate (24\%). The average family size is 6.35 and 4.89 for participants and non-participants respectively. Available active family labor in adult equivalent for participants is 3.22 and 2.61 for non-participants. Average land holding size for participants is 1.53 and 1.05 hectare for non-participants. The average owned livestock size in TLU is 8.91 and 4.48 for participants and non- participants respectively.

Table 1. Descriptive statistics of household level data $(n=300)$ used in the econometric analysis

\begin{tabular}{|c|c|c|c|c|c|c|c|}
\hline \multirow[b]{2}{*}{ Variables } & \multicolumn{2}{|c|}{ All sample } & \multicolumn{2}{|c|}{ Participant } & \multicolumn{2}{|c|}{ Non-participant } & \multirow[b]{2}{*}{ P-value } \\
\hline & Mean & Std.dev & Mean & Std.dev & Mean & Std.dev & \\
\hline Age of Household head (HH) (years) & 45.70 & 10.07 & 45.45 & 10.02 & 46.09 & 10.14 & 0.303 \\
\hline Sex of HH $(1=$ male, $0=$ female $)$ & 0.82 & 0.38 & 1.00 & 0.00 & 0.54 & 0.49 & 0.000 \\
\hline Education of $\mathrm{HH}(1=$ literate, $0=$ illiterate $)$ & 0.50 & 0.50 & 0.68 & 0.47 & 0.24 & 0.43 & 0.000 \\
\hline Family size & 5.77 & 1.92 & 6.35 & 1.81 & 4.89 & 1.74 & 0.000 \\
\hline Available family labor (adult equivalent) & 2.98 & 1.06 & 3.22 & 1.03 & 2.61 & 1.01 & 0.000 \\
\hline Owned land size (hectare) & 1.34 & 0.63 & 1.53 & 0.60 & 1.05 & 0.57 & 0.000 \\
\hline Owned livestock (Tropical Livestock Unit) & 7.14 & 3.92 & 8.91 & 3.83 & 4.48 & 2.18 & 0.000 \\
\hline Use of credit previous year $(1=$ yes, $0=$ no $)$ & 0.16 & 0.37 & 0.17 & 0.37 & 0.16 & 0.37 & 0.839 \\
\hline Number of training received for the last three years. & 3.79 & 5.31 & 5.72 & 6.08 & 0.89 & 1.10 & 0.000 \\
\hline Membership in farmer's organizations $(1=$ yes, $0=$ no $)$ & 0.81 & 0.39 & 0.96 & 0.21 & 0.58 & 0.49 & 0.000 \\
\hline Involvement in kebele administration work $(1=$ yes, $0=$ no $)$ & 0.25 & 0.44 & 0.46 & 0.49 & 0.01 & 0.10 & 0.000 \\
\hline
\end{tabular}


Table 2. Descriptive statistics of plot level data $(\mathrm{n}=1112)$ used in the econometric analysis

\begin{tabular}{|c|c|c|c|c|c|c|c|}
\hline \multirow[b]{2}{*}{ Variables } & \multicolumn{2}{|c|}{ All sample } & \multicolumn{2}{|c|}{ Participant } & \multicolumn{2}{|c|}{ Non-participant } & \multirow[b]{2}{*}{ P-value } \\
\hline & Mean & Std.dev & Mean & Std.dev & Mean & Std.dev & \\
\hline $\begin{array}{l}\text { Value of crop produced per hectare } \\
(\text { Birr/ha) }\end{array}$ & 12114 & 4721 & 13657 & 4834 & 9801 & 3431 & 0.000 \\
\hline Seed type $(1=$ improved, $0=$ local $)$ & 0.43 & 0.49 & 0.53 & 0.50 & 0.27 & 0.44 & 0.000 \\
\hline Fertilizer used per hectare (kg/ha) & 129.80 & 91.55 & 154.25 & 95.48 & 93.15 & 71.10 & 0.000 \\
\hline Compost used $(1=$ yes, $0=$ no $)$ & 0.18 & 0.39 & 0.23 & 0.42 & 0.10 & 0.31 & 0.000 \\
\hline Chemical used per hectare (lit/ha) & 0.29 & 0.55 & 0.36 & 0.63 & 0.18 & 0.39 & 0.000 \\
\hline Plot size (hectare) & 0.28 & 0.15 & 0.29 & 0.15 & 0.25 & 0.14 & 0.000 \\
\hline Fertile soil $(1=$ fertile, $0=$ otherwise $)$ & 0.24 & 0.43 & 0.24 & 0.43 & 0.23 & 0.42 & 0.725 \\
\hline $\begin{array}{l}\text { Medium fertile }(1=\text { medium fertile, } 0= \\
\text { otherwise) }\end{array}$ & 0.58 & 0.49 & 0.58 & 0.49 & 0.58 & 0.49 & 0.874 \\
\hline Flat slop ( $1=$ flat, $0=$ otherwise $)$ & 0.32 & 0.47 & 0.32 & 0.47 & 0.33 & 0.47 & 0.779 \\
\hline $\begin{array}{l}\text { Medium slop }(1=\text { medium flat, } 0= \\
\text { otherwise })\end{array}$ & 0.54 & 0.50 & 0.52 & 0.50 & 0.58 & 0.49 & 0.057 \\
\hline Tenure type $(1=$ Owned, $0=$ otherwise $)$ & 0.83 & 0.37 & 0.79 & 0.41 & 0.89 & 0.30 & 0.000 \\
\hline $\begin{array}{l}\text { Plot distance from homestead (Walking } \\
\text { minutes) }\end{array}$ & 16.70 & 15.52 & 17.44 & 15.36 & 15.58 & 15.70 & 0.050 \\
\hline $\begin{array}{l}\text { Amount of labor used per plot (person } \\
\text { days/ha) }\end{array}$ & 29.98 & 10.41 & 31.98 & 11.39 & 26.97 & 7.84 & 0.000 \\
\hline $\begin{array}{l}\text { Amount of draft power used per plot (oxen } \\
\text { days/ha) }\end{array}$ & 20.03 & 10.21 & 22.45 & 10.83 & 16.39 & 7.96 & 0.000 \\
\hline Number of Ploughing frequency & 4.92 & 1.41 & 5.11 & 1.41 & 4.63 & 1.38 & 0.000 \\
\hline
\end{tabular}

*Average market prices were used to estimate aggregate crop production at the plot level, therefore production estimates are not affected by variation in local price.

Access to credit remains very low for majority of sample households. Only $17 \%$ of participants and $16 \%$ of non-participants had access to credit. About $96 \%$ of participants and $58 \%$ of non-participants were members of farmers' organization. Moreover, about $46 \%$ of participant farmers are involved in kebele administration whereas the non-participant's involvement in kebele administration is only $1 \%$.

The average value of crop produced per hectare is 13657 Birr for participants and 9801 Birr for non- participants. The amount of inorganic fertilizer, chemical (pesticide and herbicide), and seed inputs used per hectare were computed from the actual amounts of those inputs used on each plots standardized to a per hectare level. Accordingly, the average intensity of fertilizer used per hectare by the sample households is $129 \mathrm{~kg}, 154 \mathrm{~kg}$ and $93 \mathrm{~kg}$ for all sample plots, plots of participant and non-participants respectively. This result is consistent with findings of Zerfu and Larsony (2011). The average intensity of chemical use rate by participants was 0.36 liters per hectare whereas non participants used 0.18 liters per hectare. Average plot size is $0.28,0.29$ and 0.25 for all farmers, participants and non-participants respectively. Generally the descriptive statistics result indicates that there is significant difference between participants and non-participants in terms of household characteristics, resource endowment, input use and productivity without controlling other factors. Therefore, our next question is what would happen if other factors are controlled? The different models used in this study could give the answer.

\subsection{Ordinary Least Square Results (OLS)}

The results presented in Table 3 show that participation in extension program leads to increased farm productivity by about $6 \%$. However, to measure the benefit of participation in the program in terms of farm productivity, it is necessary to take in to account the fact that, individuals those who participated might have produced higher production even if they had not participated. That is, there may be unobserved factors (e.g., ability) that increases the likelihood of participation in the program that in turn increase productivity. When this is the case the impact of the program would be overestimated by simply regressing farm productivity on a binary variable that indicates participation in the extension program. To control this sample selection bias, we estimated Equations (4) and (5) together using treatment effect model and the result is presented in the following section. 


\subsection{Heckman Treatment Effect Model (HTEM) Results}

\subsubsection{Determinants of Extension Program Participation}

The probit model for AE program participation shows that all variables except distance to extension center are significant determinants of participation in the current agricultural extension program. The model correctly predicted $70 \%$ of observed characteristics of participants and non- participants. The likelihood of participation in the extension program is affected significantly by age, education, livestock ownership, adult equivalent, use of oxen power, membership in farmers' organizations and involvement in kebele administration.

The negative and significant impact of household head age on the probability of joining the extension program indicates the lower likelihood of older farmer's participation in the program. This can be explained by the fact that older farmers are reluctant to accept new information and improved technologies. This result is consistent with studies reported by Genius et al. (2006). However, our result is contradicting with observations made by Tiwari et al. (2008); Mendola (2007). Hence, the impact of farmers' age on extension participation and/or technological adoption is ambiguous as expected. Education increases the probability of joining the extension program. This is consistent with the notion that farmers with better human capital like education are among the early adopters (Gebreegziabher et al., 2011; Giovanopoulou, Nastis, \& Papanagiotou, 2011).

Table 3. Results of OLS and HTEM (Dependent variables: ln (value of crop produced/ha) and AE participation $(1 / 0)$

\begin{tabular}{|c|c|c|c|c|c|c|}
\hline & OLS & & HTEM & & Probit & \\
\hline Variables & Coef. & Std.err. & Coef. & Std.err. & Coef. & Std.err. \\
\hline AE participation & $0.0606^{* *}$ & 0.0265 & $0.179 * * *$ & 0.0445 & & \\
\hline Sex of HH & $0.0685^{* * *}$ & 0.0256 & $0.0482 *$ & 0.0281 & & \\
\hline Age of $\mathrm{HH}(\ln )$ & $-0.0847 * *$ & 0.0427 & $-0.0753 *$ & 0.0418 & $-0.949 * * *$ & 0.289 \\
\hline Education of $\mathrm{HH}$ & -0.0132 & 0.0189 & $-0.0425 * *$ & 0.0210 & $0.852 * * *$ & 0.116 \\
\hline Owned livestock (ln) (TLU) & $0.0403 * *$ & 0.0165 & 0.0061 & 0.0197 & $1.463 * * *$ & 0.145 \\
\hline Plot size (ln) (ha) & $0.0917 * *$ & 0.0366 & $0.0729 * *$ & 0.0358 & & \\
\hline Flat slop & $0.0778 * *$ & 0.0340 & $0.0758 * *$ & 0.0306 & & \\
\hline Medium slope & 0.0308 & 0.0323 & 0.0317 & 0.0278 & & \\
\hline Fertile soil & $0.330 * * *$ & 0.0324 & $0.337 * * *$ & 0.0303 & & \\
\hline Medium fertile & $0.247 * * *$ & 0.0283 & $0.250 * * *$ & 0.0244 & & \\
\hline Tenure type & 0.0034 & 0.0253 & -0.0074 & 0.0243 & & \\
\hline Seed type & $0.1830 * * *$ & 0.0231 & $0.1750 * * *$ & 0.0222 & & \\
\hline Fertilizer (kg/ha) & $0.0013^{* * *}$ & 0.0001 & $0.0013 * * *$ & 0.0001 & & \\
\hline Compost & $0.1260 * * *$ & 0.0314 & $0.1260 * * *$ & 0.0285 & & \\
\hline Agro chemicals (lit/ha) & $0.0307 * *$ & 0.0153 & 0.0253 & 0.0161 & & \\
\hline $\begin{array}{l}\text { Plot distance from home stead(ln) } \\
\text { (walkingminute) }\end{array}$ & 0.0028 & 0.0091 & 0.0020 & 0.0088 & & \\
\hline Draft power (ln) (oxen day/ha) & $0.1550 * * *$ & 0.0459 & $0.150 * * *$ & 0.0410 & & \\
\hline Labour (ln) (person day/ha) & $0.1370 * * *$ & 0.0418 & $0.124 * * *$ & 0.0397 & & \\
\hline Ploughing frequency & $0.0216^{* *}$ & 0.0097 & $0.0224 * *$ & 0.0094 & & \\
\hline Sitedummy_Enerata (cf:Kebi) & 0.0267 & 0.0240 & 0.0255 & 0.0225 & & \\
\hline Sitedummy_Wonka & $0.1060 * * *$ & 0.0201 & $0.105 * * *$ & 0.0212 & & \\
\hline Cropdummy_Wheat (cf:Maize) & 0.0599 & 0.052 & 0.0523 & 0.0447 & & \\
\hline Cropdummy_teff & $0.2080^{* * *}$ & 0.053 & $0.201 * * *$ & 0.0458 & & \\
\hline Adult equivalent & & & & & $0.178 * * *$ & 0.062 \\
\hline Owned land (ha) & & & & & $0.321 * *$ & 0.118 \\
\hline Kebele administration & & & & & $1.572 * * *$ & 0.257 \\
\hline Membership in farmers' organizations & & & & & $1.292 * * *$ & 0.172 \\
\hline Oxen days & & & & & $0.428 * * *$ & 0.101 \\
\hline $\begin{array}{l}\text { Plot distance from extension center }(\mathrm{ln}) \\
\text { (walking minute) }\end{array}$ & & & & & -0.115 & 0.077 \\
\hline Lambda & & & $-0.0904 * * *$ & 0.0279 & & \\
\hline Constant & $7.477 * * *$ & 0.222 & $7.534 * * *$ & 0.212 & -1.64 & 1.087 \\
\hline Observations & 1112 & & 1112 & & 1112 & \\
\hline R-squared & 0.567 & & & & & \\
\hline $\begin{array}{l}\text { LR test of indep. eqns. }(\text { rho }=0): \text { chi } 2(1) \\
=8.37 \quad \text { Prob }>\text { chi } 2=0.0038\end{array}$ & & & & & & \\
\hline
\end{tabular}


As hypothesized, all wealth indicator variables have significant effect on the probability of participation. One more tropical livestock unit increases the probability of participation in the extension program by about $14 \%$. Owned land and family size in adult equivalent scale also increases the likelihood of participation. One of the characteristics of Ethiopian agriculture is its labour intensive nature; hence, households who have large number of family size in adult equivalent scale have high likelihood of participation in the extension program.

As expected, use of intensive oxen power is positively significant with participation. This implies that farmers who are believed to be hard-working have a high chance of joining the extension program and other similar development interventions in a bid to improve their productivity. However, the measurement used to characterize a hardworking farmer is still a subject of refinement in future researches.

Membership in farmers' organization has positive significance for the probability of participation in the extension program as expected and consistent with past findings (Benin et al., 2011; Abebaw \& Haile, 2013).

Involvement in kebele administration has the highest coefficient value among all the variables which affect the likelihood of participation. This implies that being affiliated with kebele administration, which is a nonfarm related activity, increases significantly the likelihood of farmers to join the extension program. This is due to lack of clear boundary between the extension program and the political administration which often share common human and material resources. For instance, as explained in our assumption, development agents often work closely with development team who are the major components of the kebele structure established by the government. The development team has also political functions, such as mobilizing support and votes for the ruling party (Cohen \& Lemma, 2011; Birhanu, 2012). Hence, it is not surprising that being in a position to involve in kebele administration increases the probability of participation in government sponsored extension program. Previous studies show that involving in local administration facilitates access to credit and fertilizer because these supplies are channeled through local agencies (Ayalew \& Deininger, 2012; Zerfu \& Larsony, 2011). Furthermore other studies show that implementation modalities are given to local agencies, so that the system is potentially open to local influence (DSA, 2006). This fact is confirmed by World Bank (2010) report; politicians provide public services to clients in exchange for political advantage. This, in turn, leads to inequality in service provision, typically to the disadvantage of women and the poor.

\subsubsection{Impact of Extension Program Participation on Farm Productivity}

The result from HTEM in Table 3 shows that participation in AE increases farm productivity by about $20 \%$. Unexpectedly the HTEM estimation for the effect of AE participation on productivity is higher compared to OLS estimation (6\%), which was estimated without treating the endogenity of extension participation. The inverse mills ratio is negatively significant which indicates the presence of serious selection bias, due to the fact that program participants were selected by other nonagricultural related affiliations such as involvement in kebele administration (Table 3).

Other factors which have positive influence on farm productivity were sex of household head, age, plot size, soil quality, slope of the plot, use of improved seed, amount of inorganic fertilizer, application of compost, ploughing frequency, labour and oxen power. All significant variables have the expected signs. Male-headed households have 5\% higher farm productivity than female headed households. The result is consistent with literatures which deals with the existence of gender variation in productivity (Pender \& Gebremedhin, 2007) due to constraints related to labor, resource endowment, access to information and cultural taboo.

According to our result, as age increases farm productivity decreases. This could be attributed to the reason that getting older might pose disadvantages in agriculture because most of the work is physically demanding and also because older household heads might be too conservative to try new and more efficient techniques that could help to increase farm productivity. This result is consistent with the findings of GulUnal (2008) and Dong, Lu, and Featherstone (2010).

Despite the importance of education in increasing farm productivity (Alene \& Manyong, 2007; Gebremedhin et al., 2009), surprisingly its effect was negatively significant. This could be partly attributed to the fact that educated farmers are involved in non-agricultural related activities (e.g. kebele administration in this study context), which would consume much of their farming time. However this is a tentative hypothesis to explain the unexpected result and needs further empirical study.

Plot size is positively significant with farm productivity. An increase in plot size by one hectare could increase yield by about $0.073 \%$. This finding is consistent with earlier observations by Sharma et al. (1999), Lundvall and Battese (2000), and Alvarez and Arias (2004), who have all reported a positive relation between average land productivity and land size. 
As expected, crop yield on fertile soil is higher due to the good quality advantage of such soils. Ploughing frequency has also significant positive effect for farm productivity. Similarly improved seed use increases productivity by $19 \%$, indicating the relative importance of promoting improved seed to increase crop productivity in Ethiopia. Application of compost increases productivity by 13\%. This reinforces the importance of soil fertility management in the Ethiopian agriculture. An increase in fertilizer use by about $50 \mathrm{~kg} / \mathrm{ha}$ increases yield by about $7 \%$. Note 7

\subsection{Propensity Score Matching Results}

As shown in Table 4, the propensity scores for each observation is calculated using logit model to predict the conditional probability of participation in AE program. The empirical model for AE participation correctly predicts $71.24 \%$ of the sample observations. The region of common support for the distribution of estimated propensity scores of participants and non-participants ranges between 0.014763 and 0.900497 . Observations whose propensity score lies outside this range are discarded. The distributions of the propensity scores are plotted in Figure 3.

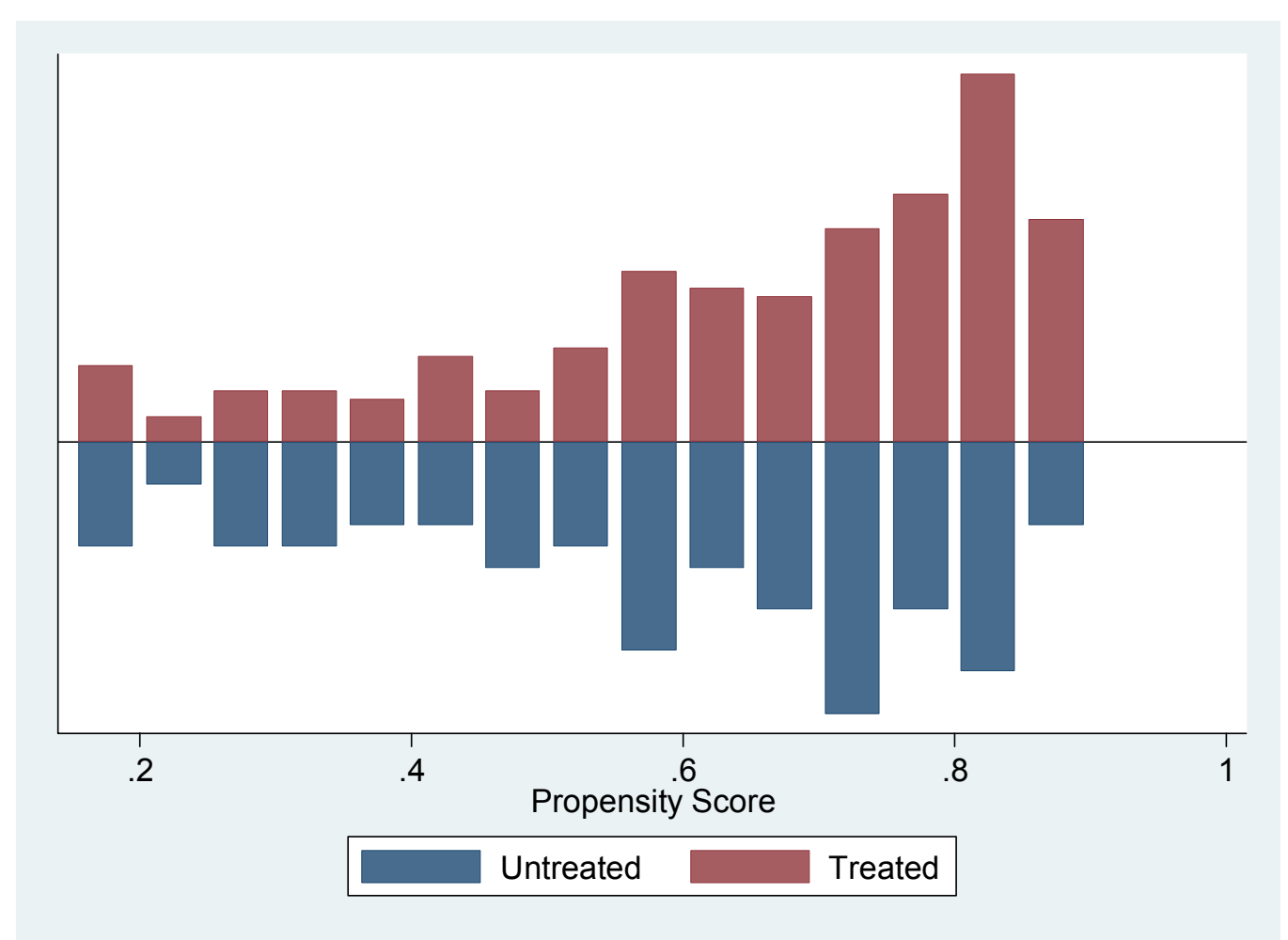

Figure 3. Propensity score distribution of matched samples

Most of the covariates in the logit model have the expected sign and comply with our previous result. The estimation results indicate that participation in AE program is strongly associated with the household's demographic characteristics and resource endowment as well as membership in farmers' organization and involvement in kebele administration. This result confirms again involvement in kebele administration, livestock ownership, and membership in farmers' organizations according to their importance order play a significant role on the likelihood of participation in extension program. From this, it can be generalized that the current agricultural extension program in Ethiopia is not targeting the majority poor. This finding is in line with the work by Lefort (2010) who reported that wealthier farmers are forcibly enrolled in the ruling party and appointed as model farmers who received privileged access to credit, state-controlled agricultural inputs, and technical knowledge spread by development agents. 
Table 4. Estimation of the propensity score (Dependent variable: AE participation 1/0)

\begin{tabular}{lll}
\hline Variables & Coef. & Std.err. \\
\hline Age of HH(ln) & $-1.487^{* * *}$ & 0.541 \\
Education of HH & $1.479^{* * *}$ & 0.209 \\
Owned livestock(ln) & $2.582^{* * *}$ & 0.272 \\
Owned land & $0.419^{* *}$ & 0.156 \\
Adult equivalent & $0.302^{* * *}$ & 0.108 \\
Oxen days (ln) & $0.745^{* * *}$ & 0.181 \\
Plot distance from extension center(ln) & -0.154 & 0.145 \\
Kebele administration & $2.987^{* * *}$ & 0.526 \\
Membership in farmers' organizations & $2.348^{* * *}$ & 0.331 \\
Sitedummy_Enerata(cf:Kebi) & -0.009 & 0.259 \\
Sitedummy_Wonka & -0.068 & 0.243 \\
Constant & $-3.820^{*}$ & 2.048 \\
Observations & 1112 & \\
Pseudo R & & \\
Model prediction rate: $71.24 \%$ & 0.5354 & \\
\hline *p $<0.1$. & & \\
\hline
\end{tabular}

\subsubsection{Average Treatment Effect on the Treated}

The PSM method is employed in estimating the impact of participation in agricultural extension on farm productivity. The impacts are estimated using alternative estimators to ensure robustness. As indicated in Table 5, all the matching estimators show that participation in agricultural extension program has a positive and statistically significant effect on farm productivity. To ensure the reliability of the estimated results, assessment on the overlap and unconfoundedness assumptions are made.

Table 5. Estimating the ATT using different matching methods

\begin{tabular}{lll}
\hline Matching estimators & Coefficient & t-statistics \\
\hline Kernel matching & $0.203^{* * *}$ & 4.738 \\
Stratification matching & $0.190^{* * *}$ & 3.289 \\
Radius matching & $0.175^{* * *}$ & 2.763 \\
Nearest Neighbor matching & $0.327^{* * *}$ & 3.288 \\
\hline
\end{tabular}

Significance levels are based on bootstrapped standard errors with 50 replications.

$* * * \mathrm{p}<0.01$.

\subsubsection{Assessment on the Overlap and Unconfoundedness Assumptions}

To evaluate the overlap assumptions we checked whether the balancing requirements of PSM are satisfied in our data. The balancing test in Table 6 indicates that the covariates of the two matched groups are well balanced in contrast to the unmatched samples presented in Table 1. All results of normalized differences between the two matched groups are small, suggesting that the overlap assumption is reasonable. Imbens and Wooldridge (2009) consider a normalized difference greater than 0.25 (in absolute value) to be substantial to detect any lack of overlap. In addition as shown in Figure 3 the two groups have substantial overlap in their propensity score distribution. 
The placebo regression (Table A1) was employed using age of spouse of the household head as a dependent variable including AE participation and similar variables used in the estimation of the propensity scores. The dependent variable is known a priori not to be caused by $\mathrm{AE}$ participation. The result shows that $\mathrm{AE}$ participation does not have influence on the dependent variable, suggesting that there are no significant omitted variables that affect the impact estimates obtained by PSM method. Therefore, the unconfoundedness assumption can be maintained and the causal interpretation of the results is plausible.

Table 6. Balancing test of matched samples

\begin{tabular}{|c|c|c|c|c|c|}
\hline \multirow[t]{2}{*}{ Variable } & \multicolumn{2}{|r|}{ AE participants } & \multicolumn{2}{|c|}{ Non-participants } & \multirow{2}{*}{$\begin{array}{c}\text { Normalized } \\
\text { difference }(\Delta x)\end{array}$} \\
\hline & Mean & Standard deviation & Mean & Standard deviation & \\
\hline Age of HH $(\ln )$ & 3.823 & 0.258 & 3.823 & 0.206 & 0.00 \\
\hline Education of $\mathrm{HH}$ & 0.451 & 0.498 & 0.377 & 0.487 & 0.07 \\
\hline Owned livestock (ln) & 1.955 & 0.361 & 1.84 & 0.336 & 0.13 \\
\hline Owned land size & 1.411 & 0.539 & 1.369 & 0.647 & 0.03 \\
\hline Adult equivalent & 3.148 & 1.037 & 3.043 & 1.004 & 0.07 \\
\hline Oxen days (ln) & 2.897 & 0.520 & 2.825 & 0.521 & 0.06 \\
\hline Plot distance from extension center $(\ln )$ & 3.426 & 0.654 & 3.354 & 0.721 & 0.05 \\
\hline Kebele administration & 0.040 & 0.199 & 0.018 & 0.135 & 0.03 \\
\hline Membership in farmers' organizations & 0.977 & 0.148 & 0.918 & 0.275 & 0.07 \\
\hline Sitedummy_Enerata(cf:Kebi) & 0.294 & 0.456 & 0.295 & 0.458 & 0.00 \\
\hline Sitedummy_Wonka & 0.406 & 0.492 & 0.336 & 0.475 & 0.13 \\
\hline
\end{tabular}

Generally, all the estimated results obtained from the different models confirm that AE participation in the study area have increased farm productivity. However, the overall level of farm productivity observed in this study for the three case study crops (teff, wheat and maize) is still low compared to the target yield set by the regional extension program based on farmers' field conditions and research stations (Table 7). For instance average teff yield observed form extension participants (16 quintal/ha) is less by half from the extension targets (20-32 quintal/ha). Similarly, the yield levels attained by participant farmers for wheat and maize were less by $1 / 3$ from the set target for the corresponding crops (43-58 quintal/ha and 70-107 quintal/ha). Several reasons could explain these discrepancies. Our field investigation and review of past researches (Abate, 2007; Kasa, 2008) show that the extension implementation in Ethiopia is constrained by a number of factors such as supply-push rather than demand-pull approach, poorly organized technology multiplication system, absence of institutional pluralism, low technology adoption rate, shortage of basic training for extension staff and others. For example in our study average application of fertilizer, improved seed and compost use rates were $129 \mathrm{~kg} / \mathrm{ha}, 42 \%$ and $18 \%$, respectively, which are much lower compared to the recommended rates. Besides, credit users in the study area were only $16 \%$, influenced by the nature of credit arrangements that reduces the attractiveness of input uptake. To be eligible, a farmer must have repaid all previous loans (Dercon, 2000). Inconvenient payback time and lack of interest due to the tendency of farmers to avoid risk in instances of crop failure are other factors for farmers' low use of credit (Carlesson, Kohlin, Mekonnen, \& Yusuf, 2005). Farmers who participated in our group discussion explained lack of quality improved seed, high price of fertilizers, limited technology choices and inconvenient loan system are the major constraints to adopt improved technologies promoted by the extension program. Furthermore our focus group discussion and field survey revealed that no single farmer has been visited by researchers implying the missing link between research and extension. 
Table 7. Comparative average yields (quintal/hectare) of the three main crops grown in the study area

\begin{tabular}{lccc}
\hline Type of crops & $\begin{array}{c}\text { Participants' } \\
\text { yield }\end{array}$ & $\begin{array}{c}\text { Targeted yield } \\
\text { on farmers plot }\end{array}$ & $\begin{array}{c}\text { Yield obtained } \\
\text { from research stations }\end{array}$ \\
\hline Teff & 16 & 20 & 32 \\
Wheat & 21 & 43 & 58 \\
Maize & 25 & 70 & 107
\end{tabular}

Average yield obtained by participants is calculated from sample plots taken by our study. Average targeted yield on farmers plot and yield obtained by research station is taken from a guideline compiled by Agriculture and Rural Development Office of the Amhara National Regional state (2011).

\section{Conclusion}

This study evaluates the effect of agricultural extension program participation on farm productivity using cross-sectional data collected in three kebeles from the Ethiopian highlands. Even though the overall impact of extension program participation cannot be known for certain because of the lack of reasonably accurate baseline data for comparison, this study employs a bench mark OLS, treatment effect model and propensity score matching methods to mitigate some of the challenges in the estimation of effect of agricultural extension participation on farm productivity.

Our model estimations indicate the positive effect of extension participation on farm productivity. However, in spite of its positive effect, our finding clearly shows the existence of selection bias which tends to target relatively wealthier farm households and those affiliated to kebele administration, which is not directly related to farm productivity. Furthermore, the program has been constrained by insufficient and/or poor quality farm inputs, such as selected seeds, and services like credit and training. As a result, the observed overall farm productivity is less by about half than the target set by the extension program.

Therefore, in order to improve the benefits to be gained through agricultural extension program participation, the following constraints need serious consideration. First, the extension program should avoid entry barriers and this requires maintaining a clear boundary between the program and the local politics which is missing at the moment. Second, improved access to diversified and quality agricultural inputs still remain critically important. Third, the local government should create the necessary asset portfolio among the poor due to the fact that resource poor farmers in Ethiopia lack the necessary means to implement extension advices.

We acknowledge, however, that our results cannot be generalized at the national level since the sample was not representative of the entire country. Hence to get more representative figure about the impact of the program at national level conducting similar studies further dealing with a wider sample size coverage and time series data that considers other aspects of the national extension program is important.

\section{References}

Abate, H. (2007). Review of extension systems applied in Ethiopia with special emphasis to the participatory demonstration and training extension system. Food and Agriculture Organization of the United Nations, (unpublished), Addis Ababa, Ethiopia.

Abate, T., Shiferaw, B., Gebeyehu, S., Amsalu, B., Negash, K., Assefa, K., ... Hagmann, J. (2011). A systems and partnership approach to agricultural research for development: Lessons from Ethiopia. Outlook on Agriculture Journal, 40(3), 213-220. http://dx. doi.org/10.5367/oa.2011.0048

Abebaw, D., \& Haile, M. G. (2013). The impact of cooperatives on agricultural technology adoption: Empirical evidence from Ethiopia. Food policy, 38, 82-91. http://dx.doi.org/10.1016/j.foodpol.2012.10.003

Alene, A. D., \& Manyong, V. M. (2007). The effects of education on agricultural productivity under traditional and improved technology in Northern Nigeria: An Endogenous Switching Regression Analysis. Empirical Economics, 32,141-159.

Alvarez, A., \& Arias, C. (2004). Technical efficiency and farm size: A conditional analysis. Agricultural Economics, 30(3), 241-250. http://dx.doi.org/10.1016/j.agecon.2003.04.001

Anderson, J. R., \& Feder, G. (2003). Rural extension services: World Bank Policy Research Working Paper, 2976, World Bank, Washington D.C. 
Anderson, J. R., \& Feder, G. (2007). Hand book of agricultural economics, agricultural extension (pp. 2343-2372). In R. Evenson, \& P. Pingali (Eds.). Agriculture and Rural Development Department, World Bank, Washington, DC.

Angrist, J. D., \& Imbens, G. W. (1995). Two-stage least squares estimates of average causal effects in models with variable treatment intensity. Journal of the American Statistical Association, 90(430), 431-442.

Asfaw, S., Shiferaw, B., Simtowe, F., \& Lipper, L. (2012). Impact of modern agricultural technologies on smallholder welfare: Evidence from Tanzania and Ethiopia. Food policy, 37, $283-295$. http://dx.doi.org/10.1016/j.foodpol.2012.02.013

Ayalew, D., \& Deininger, K. (2012). Causes and implications of credit rationing in rural Ethiopia. The importance of spatial variation. Policy Research Working Paper, 6096, the World Bank e-Library.

Barrett, C., Reardon, T., \& Webb, P. (2001). Nonfarm income diversification and household livelihood strategies in rural Africa: Concepts, Dynamics, and Policy Implications. Food Policy, 26(4), 315-31. http://dx.doi.org/10.1016/S0306-9192(01)00014-8

Benin, S. (2006). Policies and programs affecting land management practices, input use, and productivity in the highlands of Amhara Region, Ethiopia. In J. Pender, F. Place, \& S. Ehui (Eds.), Strategies for Sustainable Land Management in the East African Highlands. Washington, DC: IFPRI.

Benin, S., Nkonya, E., Okecho, G., Randriamamonjy, J., Kato, E., Lubade, G., \& Kyotalimye, M. (2011). Returns to spending on agricultural extension: The case of the National Agricultural Advisory Services (NAADA) Program of Uganda. Agricultural economics, 42, 249-267. http://dx.doi.org/10.1111/j.1574-0862.2010.00512

Birhanu, K. (2012). The political economy of agricultural extension in Ethiopia: Economic growth and political control. Working Paper, 042 Future Agriculture.

Beshir H., Emana, B., Kassa, B., \& Haji, J. (2012). Determinants of chemical fertilizer technology adoption in North Eastern Highlands of Ethiopia: The double hurdle approach. Journal of Research in Economics and International Finance, 2, 39-49.

Caliendo, M., \& Kopeinig, S. (2008). Some practical guidance for the implementation of propensity score matching. Journal of Economic Surveys, 22, 31-72. http://dx.doi.org/10.1111/j.1467-6419.2007.00527

Carlesson, F., Kohlin, G., Mekonnen, A., \& Yusuf, M. (2005). Are agricultural extension packages what Ethiopian farmers want? A stated preference analyses, working paper No. 172, Department of Economics, Goteborg University.

Cohen, M. J., \& Lemma, M. (2011). Agricultural extension services and gender equality: An institutional analysis of four districts in Ethiopia. IFPRI Discussion Paper, 01094.

Cunguara, B., \& Moder, K. (2011). Is agricultural extension helping the poor? Evidence from rural Mozambique. Journal of African Economies, 0, 1-34. http://dx.doi.org/10.1093/jae/ejr015

Dehejia, R., \& Wahba, S. (2002). Propensity score matching methods for non-experimental causal studies. The Review of Economics and Statistics, 84(1), 151-61.

Dercon, S. (2000). Growth and poverty in Ethiopia in the 1990s: An economic perspective. Centre for the study of African Economies, Oxford University.

Dercon, S., \& Christiaensen, L. (2007). Consumption risk, technology adoption and poverty traps: Evidence from Ethiopia. World Bank Policy Research Working Paper 4527, Washington, DC: World Bank.

Dong F., Lu, J., \& Featherstone, A. M. (2010). Effects of credit constraints on productivity and rural household income in China Working Paper 10-WP 516.

DSA (Development Studies Associates). (2006). Study on improving the efficiency of input markets. Ministry of Agriculture and Rural Development, Addis Ababa, Ethiopia.

Doss, C. R., \& Morris, M. L. (2001). How does gender affect the adoption of agricultural innovations? The case of improved maize technology in Ghana. Agricultural Economics, 25, 27-39. http://dx.doi.org/10.1111/j.1574-0862.2001.tb00233.x

EEA (Ethiopian Economic Association). (2006). Evaluation of the Ethiopian agricultural extension with particular emphasis on the Participatory Demonstration and Training Extension System (PADETES).Addis Ababa, Ethiopia. 
FAO (Food and Agriculture Organization of the United Nations). (2010). Ethiopia country brief. Retrieved from www.fao.org/countries/55528/en/eth/

Feder, G., Murgai, R., \& Quizon, J. B. (2004). The acquisition and diffusion of knowledge: The case of pest management training in farmer field schools, Indonesia. Journal of Agricultural Economics, 55(2), 221-243.

Feleke, S., \& Zegeye, T. (2006). Adoption of improved maize varieties in southern Ethiopia: factors and strategy options. Food Policy, 31(5), 442-457. http://dx.doi.org/10.1016/j.foodpol.2005.12.003

Gebregziabher, G., \& Holden, S. (2011). Does irrigation enhance and food deficits discourage fertilizer adoption in a risky environment: Evidence from Tigray, Ethiopia. J. Dev. Agric. Econ., 30(10), 514-528.

Gebregziabher, K., Mathijs, E., Maertens, M., Deckers, J., \& Bauer, H. (2011). Extension participation, household income and income diversification: A system equations approach. Retrieved from www.csae.ox.ac.uk/conferences/2011-EDiA/.../437

Gebremedhin, B., Jalata, M., \& Hoekstra, D. (2009). Smallholders, institutional services, and commercial transformation in Ethiopia. Journal of Agricultural Economics, 40, 773-787. http://dx.doi.org/10.1111/j.1574-0862.2009.00414

Gebreselassie, S. (2006). Intensification of smallholder agriculture in Ethiopia: Options and scenarios. paper presented for the Future Agricultures Consortium meeting at the Institute of Development Studies.

Genius M. G., Pantzios, C. J., \& Tzouvelekas, V. (2006). Information acquisition and adoption of organic farming practices. Journal of Agricultural and Resource Economics, 31(1), 93-113.

Giovanopoulou, E., Nastis, S. A., \& Papanagiotou, E. (2011). Modeling farmer participation in agri-environmental nitrate pollution reducing schemes. Ecological economics, 70, 2175-2180.

Gozamin Woreda Finance and Economic Development sector Office Document. (2010). Allocation of budget from 2003 to 2010, East Gojam zone, Amhara Regional State.

Grepperud, S. (1996). Population pressure and land degradation: The case of Ethiopia. Journal of Environmental Economics and Management, 30(1), 18-33. http://dx.doi.org/10.1006/jeem.1996.0002

GulUnal, F. (2008). Small is beautiful: Evidence of an inverse relationship between farm size and yield in Turkey. Working Paper No. 551. The Levy Economics Institute.

Heckman, J., \& Robb, R. (1985). Alternative methods for evaluating the impact of interventions: An overview. Journal of Econometrics, 30(1), 239-267.

Heckman, J., Ichimura H., Smith J., \& Todd, P. (1997). Matching as econometric evaluation estimator: Evidence from evaluating a job-training program. Review of Economic Studies, 64, 605-654. http://dx.doi.org/10.1111/1467-937X.00044

Heckman, J., \& Navarro-Lozano, S. (2004). Using matching, instrumental variables, and control functions to estimate economic choice models. The Review of Economics and Statistics, 86(1), 30-57.

Imbens, G., \& Wooldridge, J. (2009). Recent developments in the econometrics of program evaluation. Journal of Economic Literature, 47(1), 5-86. http://dx.doi.org/10.1257/jel.47.1.5

IRIN (Integrated Regional Information Networks). (2012). Humanitarian news and analysis Ethiopia: http://www.irinnews.org/report/96154/ethiopia

Kassa, B. (2003). Agricultural extension in Ethiopia: The case of participatory demonstration and training extension system. Journal of Social Development in Africa, 18(1), 49-83.

Kassa, B., \& Abebaw, D. (2004). Challenges facing agricultural extension agents: A case study from South-Western Ethiopia. African Development Review 16(1), 139-168. http://dx.doi.org/10.1111/j.1467-8268.2004.00087

Kassa, H. (2008). Agricultural extension in Ethiopia: Historical evolution, relevant policies and challenges. In T. Assefa (Ed.), Digest of Ethiopia's national policies, strategies and programs. Addis Ababa: Eclipse Printers.

Kassie, M., Zikhali, P., Manjur, K., \& Edward, E. (2009). Adoption of sustainable agriculture practices: Evidence from a semi-arid region of Ethiopia. Natural Resources Forum, 39, 189-98. http://dx.doi.org/10.1111/j.1477-8947.2009.01224

Lefort, R. (2010). Powers - Mengist - and Peasants in Rural Ethiopia: The post-2005 Interlude. Journal of Modern African Studies, 48(3), 435-460. http://dx.doi.org/10.1017/S0022278X10000297 
Lundvall, K., \& Battese, G. E. (2000). Farm size, age, and efficiency: Evidence from Kenyan manufacturing farms. Journal of Development Studies, 36(3), 146-163.

Mendola M. (2007). Agricultural technology adoption and poverty reduction: A propensity score matching analysis for rural Bangladesh. Food Policy, 32, 372-393. http://dx.doi.org/10.1016/j.foodpol.2006.07.003

Nega, F., Mathijs, E., Deckers, J., Haile, M., Nyssen, J., \& Tollens, E. (2010). Rural poverty dynamics and impact of intervention programs up on chronic and transitory poverty in Northern Ethiopia. African Development Review, 22, 92-114. http://dx.doi.org/10.1111/j.1467-8268.2009.00229

Pender, J., \& Gebremedhin, B. (2007). Determinants of agricultural and land management practices and impacts on crop production and household income in the highlands of Tigray, Ethiopia. Journal of African Economies, 17(3), 395-450. http://dx.doi.org/10.1093/jae/ejm028

Rosenbaum, P., \& Rubin, D. (1983). The central role of the propensity score in observational studies for causal effect. Biometrika, 70(1), 41-55. http://dx.doi.org/10.1093/biomet/70.1.41

Rosenbaum, P., \& Rubin, D. (1985). Constructing a control group using multivariate matched sampling methods that incorporate the propensity score. American Statistician, 39, 33-38. http://dx.doi.org/10.2307/2683903

Rubin, D. B. (1977). Assignment to treatment group on the basis of a covariate. Journal of Educational Statistics, 2, 1-26. http://dx.doi.org/10.3102/10769986002001001

Sharma, K. R., Leung, P., \& Zaleskib, H. M. (1999). Technical, allocative, and economic efficiencies in swine production in Hawaii: A comparison of parametric and nonparametric approaches. Agricultural Economics, 20(1), 23-35. http://dx.doi.org/10.1016/S0169-5150(98)00072-3

Smith, J., \& Todd, P. (2005). Does matching overcome Lalonde's critique of non-experimental estimators? Journal of Econometrics, 125, 305-353. http://dx.doi.org/10.1016/j.jeconom.2004.04.011

Spielman D.J., Byerlee, D., Alemu, D., \& Kelemework, D. (2010). Policies to promote cereal intensification in Ethiopia: The search for appropriate public and private roles. Food Policy, 35, 185-194. http://dx.doi.org/10.1016/j.foodpol.2009.12.002

Spielman, D. J., Kelemework, D., \& Alemu, D. (2011). Seed, fertilizer, and agricultural extension in Ethiopia. Ethiopia Strategy Support Program II (ESSP II) Working Paper No 20. IFPRI.

Staatz, J., \& Dembele, N. (2007). Agriculture for development in sub-saharan Africa. Background paper for the World Development Report 2008.

Thirtle, C., Beyers, L., Ismael, Y., \& Piesse, J. (2003). Can GM technologies help the poor? The impact of Bt cotton in Makhathini Flats, KwaZulu-Natal. World Development, 31(4), 717-732.

Tiwari, K. R., Sitaula, B. K., Nyborg, I. L. P., \& Paudel, G. S. (2008). Determinants of farmers adoption of improved soil conservation technology in a middle mountain watershed of Central Nepal. Environmental Management, 42, 210-222.

UNDP. (2013). Human Development Report, New York: UNDP.

Wooldridge, J. M. (2010). Econometric analysis of cross section and panel data (volume 1 of MIT Press Books).

World Bank. (2006). Ethiopia: Policies for pro-poor agricultural growth. Washington, DC: World Bank.

World Bank. (2010). Agriculture and rural development series: Gender and governance in rural Service: Insight from India, Ghana, and Ethiopia. World Bank, Washington, D.C.

World Development Report (WDR). (2008). Agriculture for development. The World Bank, Washington, DC

Yilmaz, S., \& Venugopal, V. (2008). Local government discretion and accountability in Ethiopia. International Studies Program Working Paper 08-38, Atlanta: Georgia State University.

Zerfu, D., \& Larsony, D. F. (2011). Incomplete markets and fertilizer use: Evidence from Ethiopia. 


\section{Appendix A}

Table A1: Placebo regression result

\begin{tabular}{llll}
\hline Dependent variable: age of head's spouse & Coefficient & Standard error & P-value \\
\hline Agricultural extension participation & 0.554 & 0.653 & 0.397 \\
Age of HH(ln) & 36.37 & 1.443 & 0.001 \\
Education of HH & -0.17 & 0.517 & 0.742 \\
Owned livestock(ln) & 0.394 & 0.805 & 0.625 \\
Owned land & 0.311 & 0.502 & 0.537 \\
Adult equivalent & 0.122 & 0.258 & 0.637 \\
Oxen days (ln) & 0.012 & 0.474 & 0.979 \\
Plot distance from extension center(ln) & -0.473 & 0.416 & 0.256 \\
Kebele administration & -0.161 & 1.832 & 0.930 \\
Membership in farmers' organizations & -1.418 & 1.752 & 0.419 \\
Sitedummy_Enerata(cf:Kebi) & 1.789 & 0.676 & 0.008 \\
Sitedummy_Wonka & 1.602 & 0.606 & 0.009 \\
Constant & -99.52 & 5.21 & 0.003 \\
Number of observations & 366 & & \\
F(12,353) & 142.87 & & \\
Prob> F & 0.000 & & \\
R squared & 0.81 & & \\
\hline
\end{tabular}

\section{Notes:}

Note 1. Kebele (often translated as peasant association) is the lowest administrative unit in Ethiopia and usually.

Note 2. Teff is a small grain crop widely consumed in Ethiopia and is the main ingredient in injera ( pancake-like food).

Note 3. Kebele administration, consists of an elected kebele council (in principle 100 members), a kebele cabinet (usually comprises a manager, chairperson, agricultural extension workers, school director, representatives from women and youth associations), a social court and security persons posted in the kebele. The kebele council and executive committee's main responsibilities are preparing annual kebele development plan, ensuring the collection of land and agricultural income tax, organizing local labour and in kind contributions to development activities, resolving conflicts with in the community (Yilmaz and Venugopal, 2008).

Note 4. Birr is Ethiopian currency and during the survey period $1 \mathrm{US} \$=17$ Birr.

Note 5. The treatment effect assumes non-zero correlation between $\epsilon$ and $v$ and hence violation of this assumption can lead to biased estimation.

Note 6. Previously called mengstawi budin, or government team.

Note 7. Semi-elasticities are estimated using the following formula: $\left[\exp ^{\left(\beta_{j \Delta X_{j}}\right)}-1\right] * 100$.

\section{Copyrights}

Copyright for this article is retained by the author(s), with first publication rights granted to the journal.

This is an open-access article distributed under the terms and conditions of the Creative Commons Attribution license (http://creativecommons.org/licenses/by/3.0/). 